Article

\title{
Porous CaP Coatings Formed by Combination of Plasma Electrolytic Oxidation and RF-Magnetron Sputtering
}

\author{
Anna Kozelskaya ${ }^{1, *(D)}$, Gleb Dubinenko ${ }^{1}$, Alexandr Vorobyev ${ }^{1}$, Alexander Fedotkin ${ }^{1}{ }^{(}$, \\ Natalia Korotchenko ${ }^{2}$, Alexander Gigilev ${ }^{2}$, Evgeniy Shesterikov ${ }^{3,4}$, Yuriy Zhukov ${ }^{5}$ \\ and Sergei Tverdokhlebov ${ }^{1, *(D)}$ \\ 1 School of Nuclear Science \& Engineering, Tomsk Polytechnic University, 634050 Tomsk, Russia; \\ dubinenko.gleb@gmail.com (G.D.); alexandr.vorobyev13@gmail.com (A.V.); fedotkin_sasha@mail.ru (A.F.) \\ 2 Department of Inorganic Chemistry, Tomsk State University, 634050 Tomsk, Russia; korotch@mail.ru (N.K.); \\ gigilev@mail.tsu.ru (A.G.) \\ 3 Laboratory of Radiophotonics, V.E. Zuev Institute of Atmospheric Optics SB RAS, 634055 Tomsk, Russia; \\ shesterikov_e@mail.ru \\ 4 Nanotechnology Center, Tomsk State University of Control Systems and Radioelectronics, \\ 634050 Tomsk, Russia \\ 5 Department of Nuclear-Physics Research Methods, Saint-Petersburg State University, \\ 199034 Saint-Petersburg, Russia; YURI.ZHUKOV@prevac.ru \\ * Correspondence: kozelskayaai@tpu.ru (A.K.); tverd@tpu.ru (S.T.)
}

Received: 28 October 2020; Accepted: 17 November 2020; Published: 19 November 2020

check for updates

\begin{abstract}
The porous CaP subcoating was formed on the Ti6Al4V titanium alloy substrate by plasma electrolytic oxidation (PEO). Then, upper coatings were formed by radio frequency magnetron sputtering (RFMS) over the PEO subcoating by the sputtering of various $\mathrm{CaP}$ powder targets: $\beta$-tricalcium phosphate $(\beta-\mathrm{TCP})$, hydroxyapatite (HA), Mg-substituted $\beta$-tricalcium phosphate $(\mathrm{Mg}-\beta-\mathrm{TCP})$ and $\mathrm{Mg}$-substituted hydroxyapatite (Mg-HA), Sr-substituted $\beta$-tricalcium phosphate (Sr- $\beta$-TCP) and Sr-substituted hydroxyapatite (Sr-HA). The coating surface morphology was studied by scanning electron and atomic force microscopy. The chemical composition was determined by $\mathrm{X}$-ray photoelectron spectroscopy. The phase composition of the coatings was studied by X-ray diffraction analysis. The Young's modulus of the coatings was studied by nanoindentation test. RF-magnetron sputtering treatment of PEO subcoating resulted in multileveled roughness, increased $\mathrm{Ca} / \mathrm{P}$ ratio and Young's modulus and enrichment with $\mathrm{Sr}$ and $\mathrm{Mg}$. Sputtering of the upper layer also helped to adjust the coating crystallinity.
\end{abstract}

Keywords: plasma electrolytic oxidation (PEO); radio frequency magnetron sputtering (RFMS); calcium-phosphate $(\mathrm{CaP})$ coating

\section{Introduction}

Implant integration on the bone site, together with the bone fracture consolidation time and effectiveness, are among the most significant conditions for effective bone healing. Bioactive calcium phosphate $(\mathrm{CaP})$ coatings are assigned to improve metallic implant osseointegration and reduce bone healing time. Micro-arc oxidation (MAO) or plasma electrolytic oxidation (PEO) and radio frequency magnetron sputtering deposition (RFMS) are the most developed CaP coating deposition methods.

Compared to other surface modification methods, PEO is economically efficient and best for the deposition of bioactive coatings with open porosity [1,2]. PEO coatings are excellent for their high wear and corrosive resistance [3-6], and low residual stress on the surface due to porous morphology [7]. 
Porous morphology of the coating enhances implant osseointegration and promotes bone tissue regeneration. Moreover, the raw surface provides a higher available surface area for cell seeding and bone morphogenetic protein (BMP) adsorption [8]. Another PEO feature is the feasibility of modifying the surface of complex shape and 3D-printed implantable devices. In turn, RF-sputtered coatings are dense and known for their higher calcium-to-phosphorus $(\mathrm{Ca} / \mathrm{P})$ ratio. RFMS allows for coating deposition on the various types of materials, including ceramics and polymers. This method is variable not only due to substrate material options, but also due to the material of the sputtered target.

RFMS and PEO are also known for their disadvantages. PEO coatings can only be deposited on the surface of the valve metals [9-12]. RFMS requires expensive vacuum equipment and restricted by a low rate of deposition, which determines the low efficiency of this method [13,14]. Moreover, magnetron sputtering cannot ensure coating deposition on the inner surfaces of complex-shaped substrates. A combination of PEO and RFMS could consolidate their advantages and compensate for the drawbacks.

A combination of PEO and RFMS was used previously $[15,16]$. Park et al., revealed the effect of enhanced corrosion potential and passive current density after RFMS of Mn on the Ti-29Nb- $x \mathrm{Hf}$ substrate [15]. The molar ratio of $(\mathrm{Ca}+\mathrm{Mn}) / \mathrm{P}$ was growing with the increase in $\mathrm{Mn}$ sputtering time. Hwang et al. combined PEO and RFMS to fabricate CaP/Zn coatings on the Ti-6Al-4V [16]. Coatings RFMS with Zn showed a higher cell proliferation rate. Extended Zn RFMS leads to an increased $(\mathrm{Ca}+\mathrm{Zn}) / \mathrm{P}$ ratio, growth of the amorphous phase and increase in $\mathrm{Zn}$ corrosion rate.

In the presented study, we sputtered thin RFMS CaP coatings of various compositions to enhance the osteostimulating properties and increase the $\mathrm{Ca} / \mathrm{P}$ ratio of the $\mathrm{PEO} \mathrm{CaP}$ subcoating. An increase in $\mathrm{Ca} / \mathrm{P}$ ratio, the formation of multileveled roughness and enrichment with $\mathrm{Mg}$ and $\mathrm{Sr}$ are engaged to potentially regulate osteoblasts' and osteoclasts' functionality and enhance cell attachment and proliferation [17-20].

\section{Materials and Methods}

\subsection{Coatings Formation}

Ti-6Al-4V $10 \mathrm{~mm}$ in diameter and 1-mm-thick disks were used as substrates for coatings formation. Preparation of the surface of the samples before coating included cleaning in an ultrasonic bath in distilled water and chemical etching in an aqueous solution of nitric and hydrofluoric acids taken in volume ratios of $\mathrm{HNO}_{3}: \mathrm{HF}: \mathrm{H}_{2} \mathrm{O}=1: 2.5: 2.5$, at the temperature of $15-20{ }^{\circ} \mathrm{C}$ for $10-15 \mathrm{~s}$, followed by neutralization in a $1 \%$ aqueous solution of sodium hydroxide and repeated washing with distilled water.

PEO subcoating was formed on the "Micro-arc oxidation complex" (PEOC) designed in the Laboratory for Plasma Hybrid Systems, The Weinberg Research Center, School of Nuclear Science \& Engineering of Tomsk Polytechnic University (Tomsk, Russia). A supersaturated solution of $\mathrm{CaO}$ in $10 \% \mathrm{H}_{3} \mathrm{PO}_{4}$ with $10 \mathrm{~g} / \mathrm{L}$ dispersed hydroxyapatite (particle size up to $70 \mu \mathrm{m}$ ) was used as an electrolyte. The density and $\mathrm{pH}$ of electrolyte were $1080-1090 \mathrm{~kg} / \mathrm{m}^{3}$ and 2.03 , correspondingly. PEO subcoating was formed at the following operating mode: voltage $-320 \mathrm{~V}$, voltage rise rate- $3 \mathrm{~V} / \mathrm{s}$, pulse repetition rate $-200 \mathrm{~Hz}$, pulse duration $100 \mu \mathrm{s}$, coating formation time $-15 \mathrm{~min}$. The temperature of electrolyte was keeping about $15^{\circ} \mathrm{C}$ by cooling the bath by water flow. Coated samples were washed in distilled water and dried at $120^{\circ} \mathrm{C}$ on air for $30 \mathrm{~min}$.

Various RF magnetron sputtered upper coatings were formed by the sputtering of six different powder targets: pure $\beta$-tricalcium phosphate $(\beta-\mathrm{TCP})$, pure hydroxyapatite (HA), Mg-substituted $\beta$-tricalcium phosphate and $\mathrm{Mg}$-substituted hydroxyapatite $(\mathrm{Mg}-\beta-\mathrm{TCP}, \mathrm{Mg}-\mathrm{HA}, \mathrm{Mg}$ substitutions concentration was $1.53 \mathrm{wt} . \% \pm 0.01 \mathrm{wt} . \%)$, Sr-substituted $\beta$-tricalcium phosphate and Sr-substituted hydroxyapatite (Sr- $\beta$-TCP, Sr-HA, Sr substitutions concentration was $3.39 \mathrm{wt} . \% \pm 0.09 \mathrm{wt} . \%)$. $\beta$-TCP, Mg- $\beta$-TCP, Sr- $\beta$-TCP powders were synthesized in Riga Technical University (Riga, Latvia) [13]. HA-based powders were synthesized by microwave assisted method in Tomsk State University (Tomsk, Russia) [14]. Liquid phase synthesis of MgHA and SrHA powders was carried out using a stoichiometric ratio $\mathrm{Ca} / \mathrm{P}=1.67((\mathrm{Ca}+\mathrm{Me}) / \mathrm{P}=1.67)$ and the following reactions: 


$$
(10-x) \mathrm{Ca}\left(\mathrm{NO}_{3}\right)_{2}+6\left(\mathrm{NH}_{4}\right)_{2} \mathrm{HPO}_{4}+x \mathrm{Mg}\left(\mathrm{NO}_{3}\right)_{2}+8 \mathrm{NH}_{4} \mathrm{OH}=\mathrm{Ca}(10-x) \mathrm{Mg}_{x}\left(\mathrm{PO}_{4}\right)_{6}(\mathrm{OH})_{2}+6 \mathrm{H}_{2} \mathrm{O}+20 \mathrm{NH}_{4} \mathrm{NO}_{3}
$$

$$
(10-x) \mathrm{Ca}\left(\mathrm{NO}_{3}\right)_{2}+6\left(\mathrm{NH}_{4}\right)_{2} \mathrm{HPO}_{4}+x \mathrm{Sr}\left(\mathrm{NO}_{3}\right)_{2}+8 \mathrm{NH}_{4} \mathrm{OH}=\mathrm{Ca}(10-x) \mathrm{Sr}_{x}\left(\mathrm{PO}_{4}\right)_{6}(\mathrm{OH})_{2}+6 \mathrm{H}_{2} \mathrm{O}+20 \mathrm{NH}_{4} \mathrm{NO}_{3}
$$

where $x=0.1 ; 0.3 ; 0.5(\mathrm{~mol})$, Me-metal.

An aqueous solution of calcium nitrate was mixed with a solution of ammonium hydrophosphate in concentration 0.5 and $0.3 \mathrm{M}$, respectively. The weighed sample of magnesium or strontium nitrate was added to the calcium nitrate solution. A reactant solution $\mathrm{pH}$ value of 10-11 was reached with an aqueous solution of ammonia $(25 \%, \rho=0.9 \mathrm{~g} / \mathrm{mL})$. The mixture underwent microwave exposure with $110 \mathrm{~W}$ for $40 \mathrm{~min}$ and then was carried at room temperature for $48 \mathrm{~h}$. The precipitate was filtered, rinsed with a diluted solution of ethanol and dried until constant weight $(\sim 15 \mathrm{~h})$ at $95^{\circ} \mathrm{C}$. Dried powders were annealed for $4 \mathrm{~h}$ at $900{ }^{\circ} \mathrm{C}$.

Targets were formed by spreading powders in the hexagonal crucible with an area of $230 \mathrm{~cm}^{2}$ and a depth of $0.6 \mathrm{~cm}$. The volume was constant for all powders and equal to approximately $138 \mathrm{~cm}^{3}$. The preliminary pressure in the chamber was $10^{-3} \mathrm{~Pa}$, and the working pressure (Ar) was $0.5 \mathrm{~Pa}$. The distance between the sputtering target and the substrate was $40 \mathrm{~mm}$, power density $-4.8 \mathrm{~W} / \mathrm{cm}^{2}$, sputtering time $-7 \mathrm{~h}$ for HA-based powders and $21 \mathrm{~h}$ for $\beta$-TCP-based powders.

\subsection{Coating Thickness}

PEO sub-coating thickness was studied by the eddy current testing with the use of Konstanta 5 (KONSTANTA, Saint-Petersburg, Russia) equipment. RFMS upper coating was studied on the silicon witness samples with the use of Ellips 1891 SAG (NPK "Nanotechnology Center", Novosibirsk, Russia) spectral ellipsometer.

\subsection{Scanning Electron Microscopy (SEM)}

Coating morphology was studied on the scanning electron microscope JCM-6000 (JEOL, Tokyo, Japan) using a backscattered electron detector in a low vacuum mode. Micrographs were obtained at $15 \mathrm{kV}$ accelerating voltage and $3.5 \mu \mathrm{A}$ beam current. For better micrograph quality, all samples were preliminarily sputter-coated with gold using the SC7640 magnetron sputtering system (Quorum Technologies Ltd., Newhaven, UK).

\subsection{Atomic Force Microscopy (AFM)}

The surface morphologies of the coatings were examined using atomic force microscope (Solver-HV, NT-MDT, Moscow, Russia) operating in contact mode.

\subsection{X-ray Photoelectron Spectroscopy (XPS)}

The chemical composition of the coatings was studied using an Escalab 250Xi instrument (Thermo Fisher Scientific Inc., Saint-Petersburg, Russia) equipped with monochromatic AlK $\alpha$ radiation (photon energy $1486.6 \mathrm{eV}$ ). Total energy resolution was about $0.55 \mathrm{eV}$. Spectra were recorded in the constant pass energy mode at $100 \mathrm{eV}$ for survey spectrum and $50 \mathrm{eV}$ for element core level spectrum, using an XPS spot size of $650 \mu \mathrm{m}$. Investigations were carried out at room temperature in ultrahigh vacuum of $1 \times 10^{-9}$ mbar (in case of the use of electron-ion compensation system, Ar partial pressure was $1 \times 10^{-7}$ mbar). The library of the reference XPS spectra including the atomic registration sensitivity factors was provided by the instrument manufacturer within the Avantage Data System (Thermo Fisher Scientific Inc.). Peaks were deconvoluted using the Avantage software (version 5.977) which was set to 
a Shirley background subtraction followed by peak fitting to Voigt functions having $80 \%$ Gaussian and $20 \%$ Lorentzian character.

\subsection{X-ray Diffraction (XRD) Analysis}

Coating phase composition was studied with the use of Shimadzu XRD 6000 (Shimadzu, Tokyo, Japan) X-ray diffractometer using $\mathrm{CuK} \alpha$ radiation. Diffraction patterns were obtained in Bragg-Brentano geometry with $40 \mathrm{kV}$ accelerating voltage, $30 \mathrm{~mA}$ beam current, in the range of $10^{\circ}-80^{\circ}$ scanning angles with $1^{\circ} / \mathrm{min}$ scanning speed, $0.02^{\circ}$ scanning step and $1 \mathrm{~s}$ signal acquisition time.

\subsection{Nanoindentation}

Composite coating Young's modulus was measured with the use of Nanoindenter G200 (Agilent's Electronic Measurement, Santa Clara, CA, USA). Indentation was performed with triangular Berkovich pyramid at $50 \mathrm{mN}$ at least five times on each sample. Young's modulus was defined according to the ISO14577 [21].

\section{Results}

Two consecutive layers formed composition CaP coatings: thick PEO subcoating and thin RFMS upper coating of six different compositions. The thickness of each layer and total composite coating thickness are presented in Table 1. We observed no significant difference in the thickness of PEO subcoating on all samples, which was approximately $35 \mu \mathrm{m}$. However, the thickness of RFMS upper coating depends on the target composition and ion substitutions. $\beta$-TCP-based targets have a lower rate of sputtering comparing with HA-based targets. Another key factor affects the rate of sputtering is $\mathrm{Mg}$ and $\mathrm{Sr}$ ion substitutions. Sr substitution increases the rate of $\beta$-TCP RFMS, while Mg has no significant effect on the sputtering rate. We discussed the effect of $\mathrm{Sr}$ and $\mathrm{Mg}$ substitutions on the $\beta$-TCP RFMS rate in more detail in our previous study [22]. For HA-based upper coatings, we observed no significant effect of $\mathrm{Sr}$ and $\mathrm{Mg}$ substitution on the rate of sputtering. We revealed significant thickness differences with PEO only for the PEO + HA composite coating.

Table 1. Coating thickness.

\begin{tabular}{cccc}
\hline Group & $\begin{array}{c}\text { PEO Subcoating } \\
\text { Thickness, } \boldsymbol{\mu} \mathbf{m}\end{array}$ & $\begin{array}{c}\text { RFMS Upper Coating } \\
\text { Thickness, } \boldsymbol{\mu \mathbf { m }}\end{array}$ & $\begin{array}{c}\text { Total Composite } \\
\text { Coating Thickness, } \boldsymbol{\mu m}\end{array}$ \\
\hline PEO & $35 \pm 1.7$ & - & $35.0 \pm 1.7$ \\
PEO + HA & $36 \pm 1.0$ & $2.4 \pm 0.1$ & $38.4 \pm 1.1^{*}$ \\
PEO + Sr-HA & $36 \pm 1.0$ & $1.3 \pm 0.1^{+}$ & $37.3 \pm 1.1$ \\
PEO + Mg-HA & $34 \pm 0.5$ & $1.1 \pm 0.1^{+}$ & $35.1 \pm 0.6$ \\
PEO + $\beta$-TCP & $35 \pm 1.5$ & $0.7 \pm 0.1$ & $35.7 \pm 1.6$ \\
PEO + Sr- $\beta-$ TCP & $36 \pm 1.5$ & $1.0 \pm 0.1^{+}$ & $37.0 \pm 1.6$ \\
PEO + Mg- $\beta$-TCP & $35 \pm 1.5$ & $0.6 \pm 0.1$ & $35.6 \pm 1.6$ \\
\hline
\end{tabular}

* significant differences with PEO $(p<0.05) ;{ }^{\dagger}$ significant differences between groups of the $\beta$-TCP and X- $\beta$-TCP coatings and HA and X-HA coatings, where $\mathrm{X}$ is $\mathrm{Mg}$ or $\mathrm{Sr}(p<0.05)$.

\subsection{Composite Coating Morphology}

Close-standing highly porous groups of spheroidal structures (spherulites) form the surface of PEO subcoating (Figure 1a). The average spherulites lateral dimension varies from 5 to $20 \mu \mathrm{m}$ and open spherulites walls thickness from 1 to $1.5 \mu \mathrm{m}$. We suppose that high-temperature microplasma discharges during PEO initiate erosion and partial destruction of spherulites, which results in the formation of a sponge-like structure. On the macroscale, this sponge structure is stable after RFMS of the upper coating. Thin upper coating replicates the subcoating macrorelief. However, at high magnification, we observe crystallite-like structures on the spherulites' surfaces (Figure 1b-g). We observed a similar surface morphology for composition coatings with $\beta$-TCP-based RFMS upper 
coatings (Figure 1e-g). It should be noted that distinct dendritic crystallites cover the surface of spherulites with HA upper coating (Figure 1b). We associate this crystallization effect with an intense surface heating due to bombarding substrate by high-energy plasma particles during RFMS of the HA target.

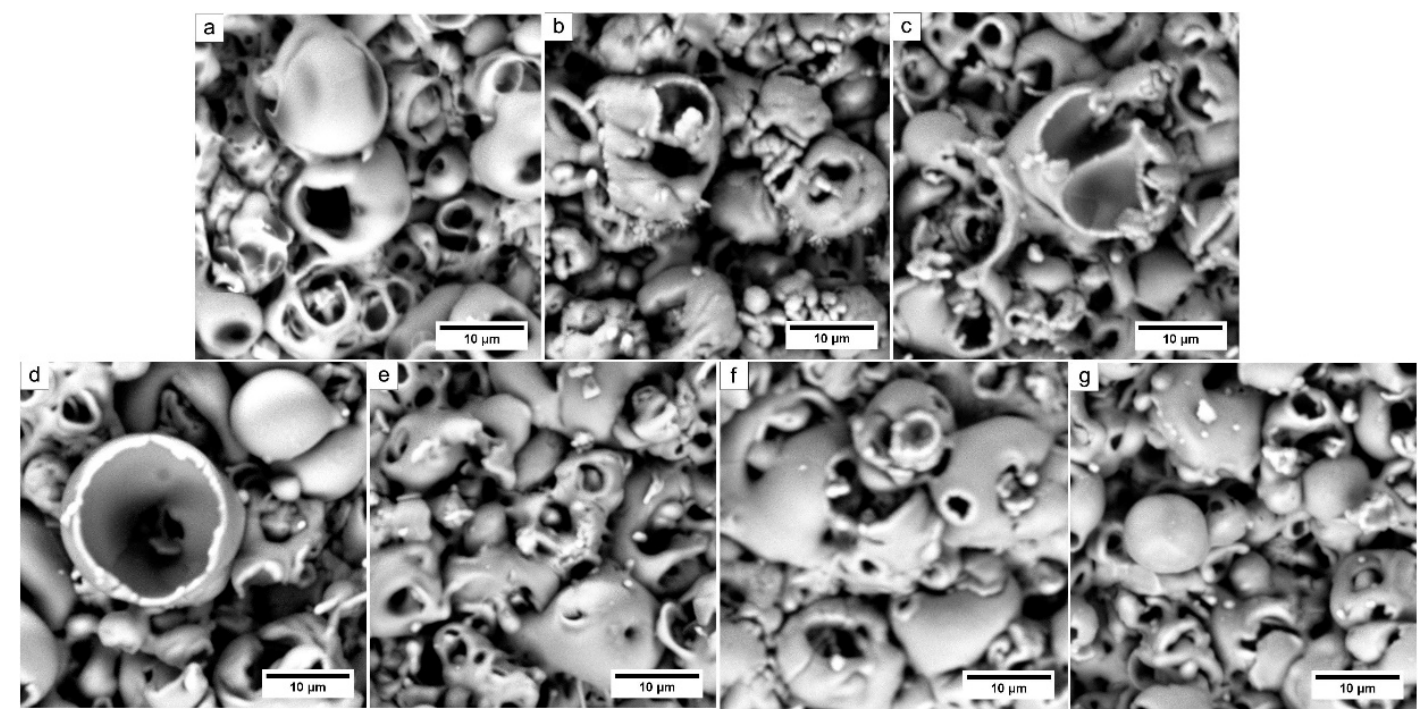

Figure 1. SEM micrographs of PEO CaP subcoating (a) and PEO + RFMS HA (b), Sr-HA (c), Mg-HA (d), $\beta$-TCP (e), Sr- $\beta$-TCP (f) and Mg- $\beta$-TCP (g) composite coatings.

An AFM study of thin RFMS surface layer showed the relationship between surface structure and composition of the sputtered target. We observed RFMS crystallites over the PEO spherulites surface in the images of composite coatings (Figure $2 \mathrm{~b}-\mathrm{g}$ ). Homogeneously distributed crystallites are clearly visible in the images of PEO + HA (Figure 2(b2)) and PEO + Mg-HA (Figure 2(d2)). HA crystallites are oval and have a $0.31 \pm 0.06 \mu \mathrm{m}^{2}$ approximate area (Figure 2(b3)). Mg-HA crystallites are smaller and near the quasi-equilibrium shape with an approximate area of $0.06 \pm 0.02 \mu \mathrm{m}^{2}$ (Figure 2(d3)). However, most of the composite coatings, including PEO + Sr-HA (Figure 2(c1-c3)), PEO + $\beta-\mathrm{TCP}$ (Figure 2(e1-e3)), PEO + Sr- $\beta$-TCP (Figure 2(f1-f3)), and PEO + Mg- $\beta$-TCP (Figure 2(g1-g3)), are formed by HA-type crystallites. Presumably, Figure $2(\mathrm{c} 3, \mathrm{f3})$ shows initial PEO spherulites with no traces of RFMS crystallites.

\subsection{Coating Phase Composition}

In the XRD patterns of all composite coatings, we observed metallic substrate $\alpha$-Ti characteristic peaks at $2 \theta=35.24^{\circ}$ (corresponding to 100 plane reflection), 38.39 $(002), 40.29^{\circ}(101), 63.24^{\circ}(110)$, $74.52^{\circ}(200), 76.47^{\circ}(112)$ and $77.71^{\circ}$ (201) (Figure 3). In the patterns of HA and Sr-HA RFMS coatings, we observed sharp peaks in hydroxyapatite $\mathrm{Ca}_{5}\left(\mathrm{PO}_{4}\right)_{3}(\mathrm{OH})$ at $2 \theta=25.85^{\circ}(002), 31.77^{\circ}(121), 32.18^{\circ}(112)$, $32.91^{\circ}(300), 34.05^{\circ}(202), 46.69^{\circ}(222)$ and $49.46^{\circ}$ (213) (Figure 3a). We also identified less intense hydroxyapatite peaks at $2 \theta=28.11^{\circ}(102), 28.93^{\circ}(210), 52.07^{\circ}(402), 53.09^{\circ}(141)$ and $70.79^{\circ}(503)$. Considering the absence of the reflection from the (211) plane, which is the strongest line of HA phase and the width and sharpness of the observed peaks, we suggest that composite coatings' RFMS with HA and Sr-HA are predominantly amorphous coatings, with the presence of the peaks in the HA crystal phase. 

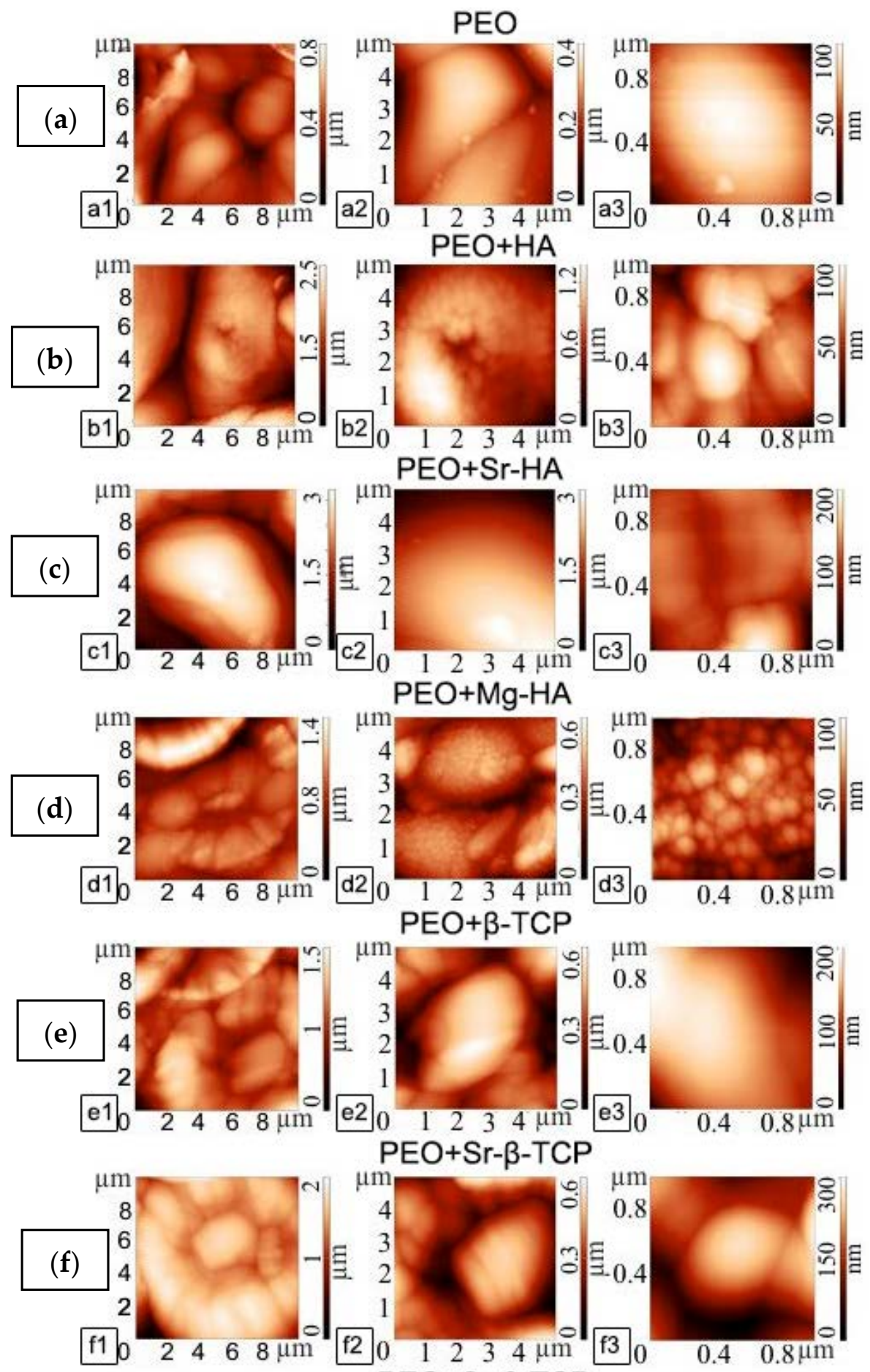

$\mathrm{PEO}+\mathrm{Sr}-\beta-\mathrm{TCP}$

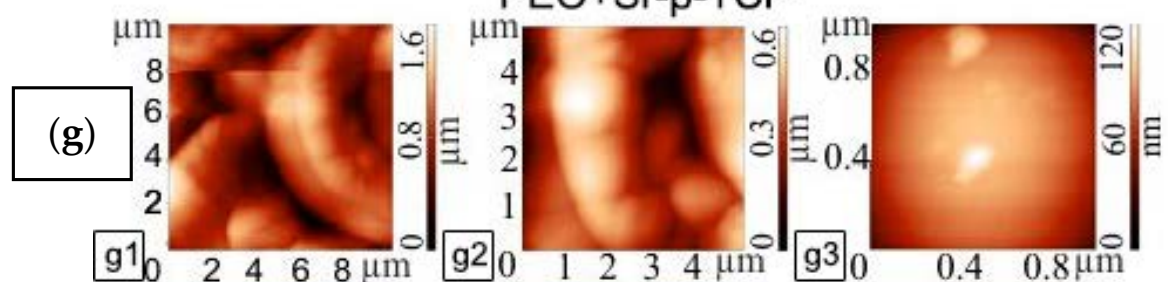

Figure 2. AFM images of CaP PEO (a) and composite PEO + RF coatings sputtered with HA (b), Sr-HA (c), Mg-HA (d), $\beta$-TCP (e), Sr- $\beta$-TCP (f), and Mg- $\beta$-TCP (g) targets. 


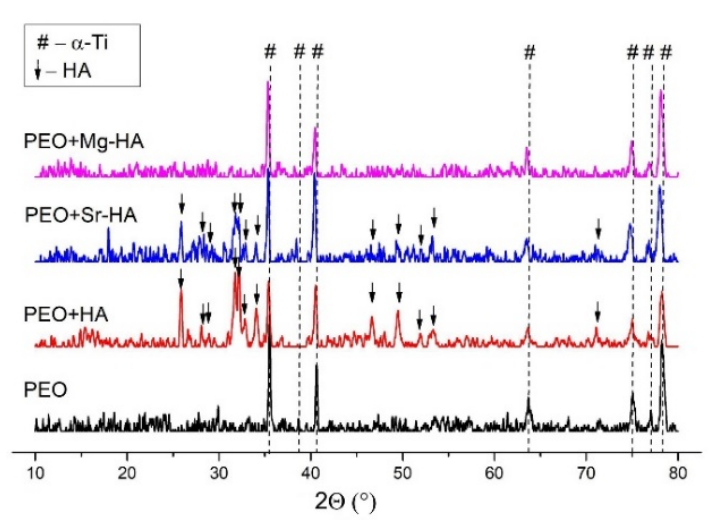

(a)

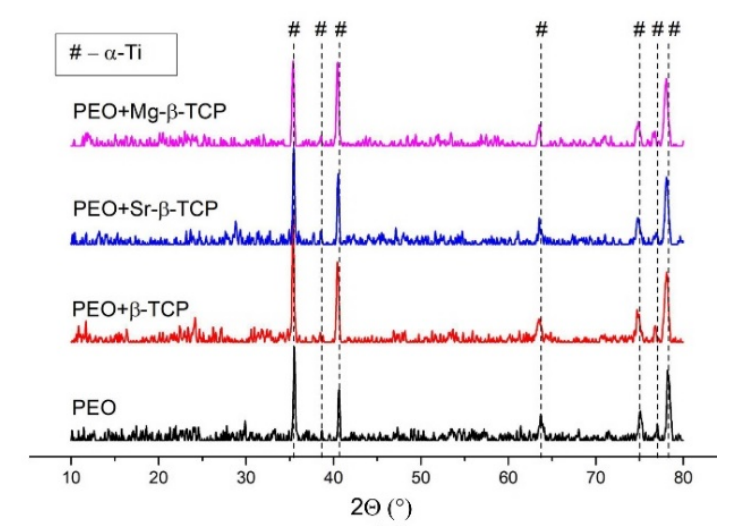

(b)

Figure 3. XRD patterns of CaP PEO and composite PEO + RF coatings sputtered with (a) HA, Sr-HA, $\mathrm{Mg}-\mathrm{HA}$; (b) $\beta$-TCP, Sr- $\beta$-TCP, Mg- $\beta$-TCP targets.

\subsection{Coating Chemical Composition}

Chemical composition of composite coatings is presented in Table 2. The compositions of coatings correspond to the chemical composition of PEO electrolyte and RFMS targets and are generally represented by Ca, P and O. Coatings' RFMS with Sr- and Mg-substituted targets contain $\mathrm{Sr}$ and $\mathrm{Mg}$, respectively.

Table 2. Chemical composition of CaP composite coatings.

\begin{tabular}{|c|c|c|c|c|c|c|c|c|}
\hline \multirow{2}{*}{ Sample } & \multicolumn{8}{|c|}{ The Content of Elements in the Coating (at.\%) } \\
\hline & $\mathbf{O}$ & $\mathrm{Ca}$ & $\mathbf{P}$ & $\mathrm{Ti}$ & C & Sr & Mg & $\mathrm{Ca} / \mathrm{P}$ \\
\hline PEO & $61.5 \pm 0.6$ & $6.0 \pm 0.3$ & $17.6 \pm 0.2$ & $3.7 \pm 0.3$ & $11.4 \pm 1.4$ & - & - & $0.34 \pm 0.02$ \\
\hline $\mathrm{PEO}+\mathrm{HA}$ & $54.9 \pm 0.8 *$ & $17.9 \pm 0.6^{*}$ & $14.7 \pm 0.5$ * & - & $12.5 \pm 0.5$ & - & - & $1.22 \pm 0.06^{*}$ \\
\hline $\begin{array}{l}\text { PEO + } \\
\text { Sr-HA }\end{array}$ & $57.7 \pm 1.8 *$ & $17.1 \pm 0.5^{*}$ & $17.0 \pm 0.5$ & - & $7.7 \pm 2.8$ & $0.5 \pm 0.04$ * & - & $1.01 \pm 0.04$ * \\
\hline $\begin{array}{c}\mathrm{PEO}+ \\
\mathrm{Mg}-\mathrm{HA}\end{array}$ & $60.0 \pm 2.0$ & $13.4 \pm 0.4$ * & $17.4 \pm 0.6$ & - & $7.9 \pm 2.9$ & - & $1.3 \pm 0.3 *$ & $0.77 \pm 0.04$ * \\
\hline $\begin{array}{l}\mathrm{PEO}+ \\
\beta-\mathrm{TCP}\end{array}$ & $59.4 \pm 1.0^{* \dagger}$ & $15.1 \pm 0.1$ *† & $16.2 \pm 0.4^{*+}$ & - & $9.3 \pm 1.4^{\dagger}$ & - & - & $0.93 \pm 0.02 *$ \\
\hline $\begin{array}{c}\text { PEO + } \\
\text { Sr- } \beta-\text { TCP }\end{array}$ & $58.3 \pm 2.5$ & $13.2 \pm 0.8^{*+}$ & $19.0 \pm 1.3^{* \dagger}$ & - & $9.0 \pm 4.7$ & $0.5 \pm 0.2 *$ & - & $0.70 \pm 0.06$ *t \\
\hline $\begin{array}{c}\mathrm{PEO}+ \\
\mathrm{Mg}-\beta-\mathrm{TCP}\end{array}$ & $62.8 \pm 0.5^{* \dagger}$ & $8.5 \pm 0.1^{* \dagger}$ & $18.3 \pm 0.3 *$ & - & $7.4 \pm 1.2 *$ & - & $2.9 \pm 0.4^{* \dagger}$ & $0.46 \pm 0.01$ *t \\
\hline
\end{tabular}

${ }^{*}$ significant differences with PEO $(p<0.05) ;{ }^{\dagger}$ significant differences between groups of the $X$ - $\beta$-TCP and $\mathrm{X}$-HA coatings, where $\mathrm{X}$ is $\mathrm{Mg}$ or $\mathrm{Sr}(p<0.05)$.

It should be noted that CaP PEO coatings are generally calcium-deficient and characterized by $\mathrm{Ca} / \mathrm{P}=0.34 \pm 0.02$. The RFMS upper coating increases the $\mathrm{Ca} / \mathrm{P}$ ratio. The $\mathrm{Ca} / \mathrm{P}$ ratio varies in the following progression: $\mathrm{PEO}<\mathrm{PEO}+\mathrm{Mg}-\beta-\mathrm{TCP}<\mathrm{PEO}+\mathrm{Sr}-\beta-\mathrm{TCP}<\mathrm{PEO}+\mathrm{Mg}-\mathrm{HA}<$ $\mathrm{PEO}+\beta-\mathrm{TCP}<\mathrm{PEO}+\mathrm{Sr}-\mathrm{HA}<\mathrm{PEO}+\mathrm{HA}$. Moreover, for both HA and $\beta-\mathrm{TCP}$, the $\mathrm{Ca} / \mathrm{P}$ ratio is greater for Sr-substituted upper coatings compared with Mg-substituted coatings.

In the XPS spectra of PEO coating, we observed typical O1s, Ti2 $p, \mathrm{Ca} 2 p, \mathrm{C} 1 s, \mathrm{P} 2 p$ and Auger's peaks corresponding to O KLL and Ca LMM (Figure 4). The Ti2 $p$ peak appears only in PEO CaP coatings' spectra at the following binding energy: Ti2 $23 / 2=459.28 \mathrm{eV}$. Generally, this peak recognizes $\mathrm{O}-\mathrm{Ti}-\mathrm{O}$ of $\mathrm{TiO}_{2}$ [23]. In composite coatings' spectra, Ti2 $p$ is not identified due to the RFMS thin $\mathrm{CaP}$ upper coating. In the spectra of composite coatings sputtered with $\mathrm{Sr}$ - and $\mathrm{Mg}$-substituted HA and $\beta$-TCP, we revealed the small peaks in $\mathrm{Sr}$ and $\mathrm{Mg}$, respectively. The typical XPS spectra of Ca2 $p$ and P2 $p$ core levels of the coatings are shown in Figure 5. The corresponding BE values of Ca2p3/2 and $\mathrm{P} 2 p 3 / 2$ of the coatings are listed in Table 3. Generally, different CaP materials show peaks at similar binding energies in the XPS spectra [24,25]. Peaks overlapping makes it difficult to distinguish different $\mathrm{CaP}$ phases in composite material. Peaks at 347.46, 133.00 and 347.46, $133.00 \mathrm{eV}$ in the spectra of $\mathrm{PEO}+\beta-\mathrm{TCP}$ and $\mathrm{PEO}+\mathrm{Sr}-\beta-\mathrm{TCP}$, respectively, correspond to Ca $2 p 3 / 2$ and $\mathrm{P} 2 p 3 / 2$ in $\mathrm{Ca}_{5}\left(\mathrm{PO}_{4}\right)(\mathrm{OH})$. 
This correlates with the XRD data. XPS analysis revealed the following relations for composite coatings (Table 3):

- $\quad \mathrm{PEO}$ and $\mathrm{PEO}+\mathrm{Mg}-\beta-\mathrm{TCP}$ coatings show the highest P2 $p$ binding energy;

- $\quad \mathrm{PEO}+\mathrm{Mg}-\beta-\mathrm{TCP}$ and $\mathrm{PEO}+\mathrm{Mg}-\mathrm{HA}$ coatings show the highest $\mathrm{Ca} 2 p$ binding energy;

- Binding energy increases by the following progression: $\mathrm{PEO}+\mathrm{Mg}-\beta-\mathrm{TCP}<\mathrm{PEO}+\mathrm{Sr}-\beta-\mathrm{TCP}<$ $\mathrm{PEO}+\beta-\mathrm{TCP}$ and $\mathrm{PEO}+\mathrm{Mg}-\mathrm{HA}<\mathrm{PEO}+\mathrm{Sr}-\mathrm{HA}<\mathrm{PEO}+\mathrm{HA}$.

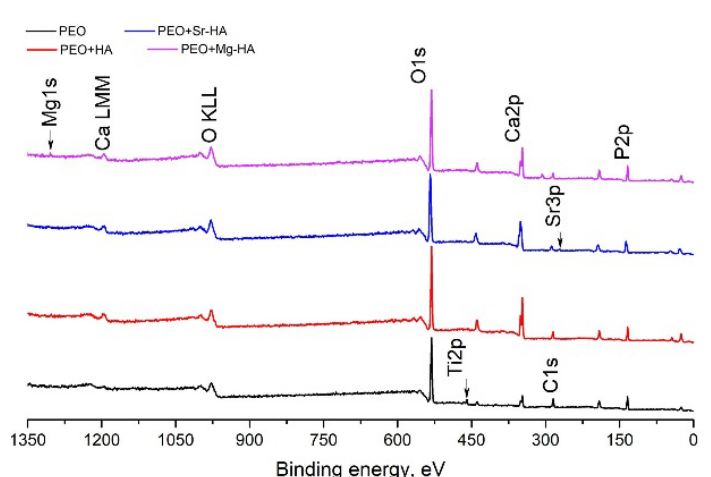

(a)

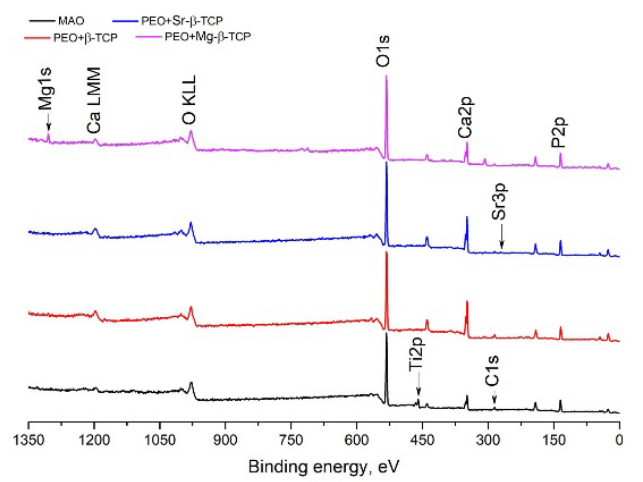

(b)

Figure 4. The XPS survey spectra for the CaP PEO (black line on Figure $4 \mathrm{a}, \mathrm{b}$ ) and composite HA (a) and $\beta$-TCP (b) RFMS coatings.

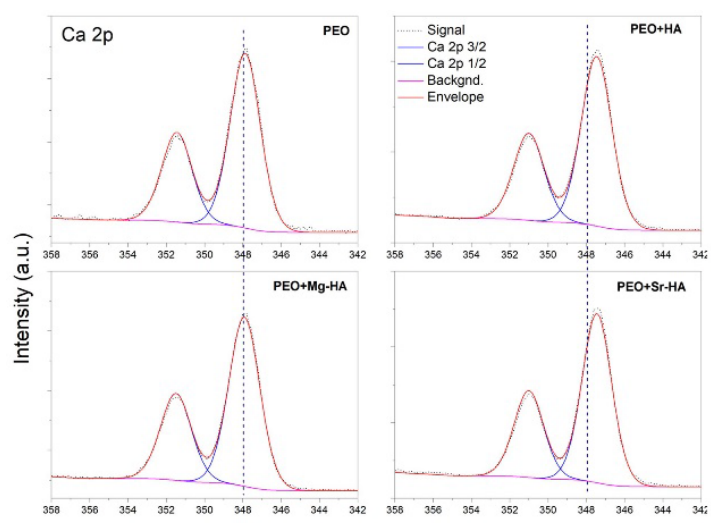

Binding Energy (eV)

(a)

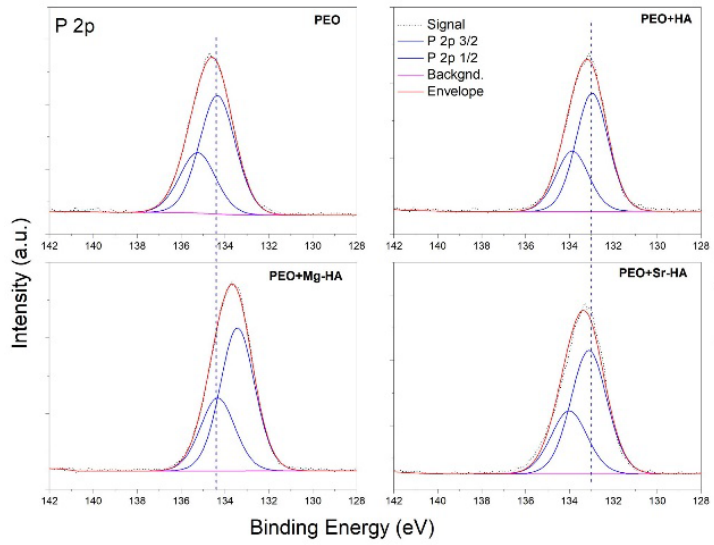

(c)

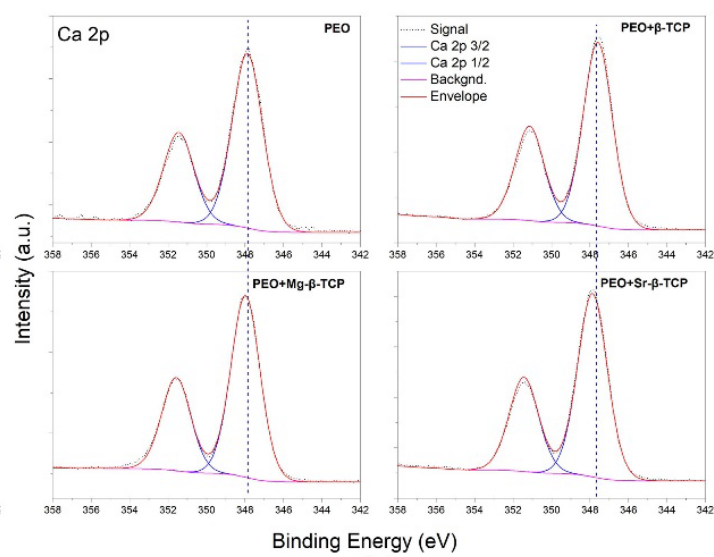

(b)

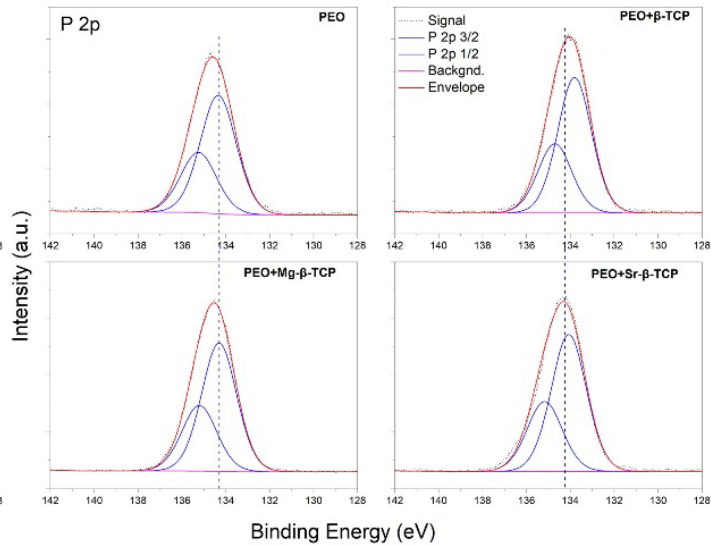

(d)

Figure 5. High-resolution XPS spectra of Ca $2 p(\mathbf{a}, \mathbf{b})$ and P $2 p(\mathbf{c}, \mathbf{d})$ core levels of composite CaP coatings. 
Table 3. Binding energy values of the Ca2p3/2 and P2p3/2 XPS peaks.

\begin{tabular}{ccc}
\hline Coating & Ca $2 p 3 / \mathbf{2}(\mathbf{e V})$ & P 2p3/2 (eV) \\
\hline PEO & 347.88 & 134.31 \\
PEO + HA & 347.46 & 133.00 \\
PEO + Sr-HA & 347.44 & 133.10 \\
PEO + Mg-HA & 347.92 & 133.43 \\
PEO + $\beta-\mathrm{TCP}$ & 347.59 & 133.80 \\
PEO + Sr- $\beta$-TCP & 347.87 & 134.07 \\
PEO + Mg- $\beta-\mathrm{TCP}$ & 347.97 & 134.31 \\
\hline
\end{tabular}

\subsection{Young's Modulus}

RFMS CaP upper coating significantly enhances PEO + Mg-HA, PEO + Sr-HA and PEO + $\beta$-TCP Young's modulus compared with the PEO subcoating (Table 4). It is important to note that the Young's modulus of all coatings under study varies in the range 15-37 GPa, which corresponds with the nanoindentation modulus of human bone [26].

Table 4. Young's modulus of CaP PEO and composite coatings.

\begin{tabular}{cc}
\hline Coating & $E_{\text {IT, }}$ GPa \\
\hline PEO & $15.4 \pm 3.8$ \\
PEO + HA & $21.3 \pm 3.7$ \\
PEO + Sr-HA & $36.6 \pm 9.5^{*}$, \\
PEO + Mg-HA & $29.8 \pm 6.8^{*}$ \\
PEO + $\beta-\mathrm{TCP}$ & $25.6 \pm 5.8^{*}$ \\
PEO + Sr- $\beta$-TCP & $19.5 \pm 4.1$ \\
PEO + Mg- $\beta-\mathrm{TCP}$ & $17.4 \pm 3.2$
\end{tabular}

* significant differences with PEO, $p<0.05 ;^{\dagger}$ significant differences between groups of the $\beta$-TCP and X- $\beta$-TCP coatings and HA and X-HA coatings, where $X$ is $\mathrm{Mg}$ or $\mathrm{Sr}, p<0.05$.

\section{Conclusions}

Composite PEO+RFMS coatings were characterized by the multileveled roughness, increased $\mathrm{Ca} / \mathrm{P}$ ratio and Young's modulus (PEO + Mg-HA, PEO + Sr-HA, PEO + $\beta-\mathrm{TCP})$. The upper RFMS CaP coating forms a thin layer over the PEO sub-coating spherulites. The RFMS of different CaP and ion-substituted $\mathrm{CaP}$ provides various coating crystallinities and are potentially beneficial in adjustable biodegradation and osseointegration. Moreover, the sputtering of ion-substituted CaP targets makes it possible to introduce into the composition of the coatings elements that bone tissue growth-stimulating $(\mathrm{Mg})$ and suppress the resorptive activity of osteoclasts $(\mathrm{Sr})$.

Author Contributions: A.K.: conceptualization, data curation, funding acquisition, supervision, investigation, methodology, validation, writing — original draft, writing—review and editing; G.D.: nanoindentation, data curation; validation; writing - review and editing; A.V.: PEO subcoating formation, data curation; validation; A.F.: upper coatings' formation by RFMS, data curation; validation; N.K.: synthesizing the powders of pure hydroxyapatite (HA), Sr-HA, Mg-HA by microwave-assisted method, data curation; validation; A.G.: synthesizing the powders of pure hydroxyapatite (HA), Sr-HA, Mg-HA by microwave-assisted method, data curation; validation; E.S.: upper coatings' formation by RFMS, data curation; validation; Y.Z.: X-ray photoelectron spectroscopy (XPS), data curation; validation; S.T.: conceptualization, resources, funding acquisition, supervision, validation. All authors have read and agreed to the published version of the manuscript.

Funding: This work was supported by the Tomsk Polytechnic University Competitiveness Enhancement Program project VIU-School of Nuclear Science and Engineering-204/2019 and project VIU-SEC B.P. Veinberg-196/2020.

Acknowledgments: Our gratitude to Liga Stipniece and Janis Locs from Riga Technical University (Riga, Latvia) for the synthesis of the $\beta$-TCP, Mg- $\beta$-TCP, Sr- $\beta$-TCP powders. We are grateful to V.P. Ignatov for consultations on the preparation of $\mathrm{CaP}$ electrolyte for PEO and valuable advice on the discussion of the experimental results. The authors are grateful to the Resource Centre "Materials Science Shared Center", part of the "Tomsk Regional Common Use Center (TRCUC)" of Tomsk State University, for XRD measurements, and the Resource Centre "Physical Methods of Surface Investigation" of Saint-Petersburg State University Research Park for XPS measurements. 
Conflicts of Interest: The authors declare no conflict of interest.

\section{References}

1. Liu, F.; Song, Y.; Wang, F.; Shimizu, T.; Igarashi, K.; Zhao, L. Formation characterization of hydroxyapatite on titanium by microarc oxidation and hydrothermal treatment. J. Biosci. Bioeng. 2005, 100, $100-104$. [CrossRef] [PubMed]

2. Parfenov, E.; Parfenova, L.; Mukaeva, V.; Farrakhov, R.; Stotskiy, A.; Raab, A.; Danilko, K.; Rameshbabu, N.; Valiev, R. Biofunctionalization of PEO coatings on titanium implants with inorganic and organic substances. Surf. Coat. Technol. 2020, 404, 126486. [CrossRef]

3. Yang, W.; Wang, P.; Guo, Y.; Jiang, B.; Yang, F.; Li, J. Microstructure and corrosion resistance of modified AZ31 magnesium alloy using microarc oxidation combined with electrophoresis process. J. Wuhan Univ. Technol. Sci. Ed. 2013, 28, 612-616. [CrossRef]

4. Rehman, Z.U.; Choi, D.; Koo, B.H. A three layer corrosion protection system for Mg-9Al-Zn alloy offered by complex fluoride ions and precipitates-based electrolytic oxidation. Surf. Coat. Technol. 2020, 393, 125804. [CrossRef]

5. Ur Rehman, Z.; Heun Koo, B.; Choi, D. Influence of complex $\mathrm{SiF}_{6}{ }^{2-}$ Ions on the PEO coatings formed on $\mathrm{Mg}-\mathrm{Al6}-\mathrm{Zn} 1$ alloy for enhanced wear and corrosion protection. Coatings 2020, 10, 94. [CrossRef]

6. Ur Rehman, Z.; Choi, D. Investigation of $\mathrm{ZrO}_{2}$ nanoparticles concentration and processing time effect on the localized PEO coatings formed on AZ91 alloy. J. Magnes. Alloy. 2019, 7, 555-565. [CrossRef]

7. Gu, Y.; Xiong, W.; Ning, C.; Zhang, J. Residual stresses in microarc oxidation ceramic coatings on biocompatible AZ31 magnesium alloys. J. Mater. Eng. Perform. 2011. [CrossRef]

8. Akin, F.A.; Zreiqat, H.; Jordan, S.; Wijesundara, M.B.J.; Hanley, L. Preparation and analysis of macroporous $\mathrm{TiO} 2$ films on Ti surfaces for bone-tissue implants. J. Biomed. Mater. Res. Part A 2001, 57, 588-596. [CrossRef]

9. Yavari, S.A.; Necula, B.S.; Fratila-Apachitei, L.E.; Duszczyk, J.; Apachitei, I. Biofunctional surfaces by plasma electrolytic oxidation on titanium biomedical alloys. Surf. Eng. 2016, 32, 411-417. [CrossRef]

10. Krząkała, A.; Kazek-Kęsik, A.; Simka, W. Application of plasma electrolytic oxidation to bioactive surface formation on titanium and its alloys. RSC Adv. 2013, 3, 19725. [CrossRef]

11. Barati Darband, G.; Aliofkhazraei, M.; Hamghalam, P.; Valizade, N. Plasma electrolytic oxidation of magnesium and its alloys: Mechanism, properties and applications. J. Magnes. Alloy. 2017, 5, 74-132. [CrossRef]

12. Jiang, B.L.; Wang, Y.M. Plasma electrolytic oxidation treatment of aluminium and titanium alloys. In Surface Engineering of Light Alloys; Elsevier: Amsterdam, The Netherlands, 2010; pp. 110-154.

13. Depla, D.; Mahieu, S.; Greene, J.E. Sputter Deposition Processes. In B Handbook of Deposition Technologies for Films and Coatings; Elsevier: Amsterdam, The Netherlands, 2010; pp. 253-296.

14. Juhasz, J.A.; Best, S.M. Surface modification of biomaterials by calcium phosphate deposition. In Surface Modification of Biomaterials; Elsevier: Amsterdam, The Netherlands, 2011; pp. 143-169.

15. Park, S.-Y.; Choe, H.-C. Mn-coatings on the micro-pore formed Ti-29Nb- $x$ Hf alloys by RF-magnetron sputtering for dental applications. Appl. Surf. Sci. 2018, 432, 278-284. [CrossRef]

16. Hwang, I.-J.; Choe, H.-C. Surface morphology and cell behavior of Zn-coated Ti-6Al-4V alloy by RF-sputtering after PEO-treatment. Surf. Coat. Technol. 2019, 361, 386-395. [CrossRef]

17. Lu, J.; Yu, H.; Chen, C. Biological properties of calcium phosphate biomaterials for bone repair: A review. RSC Adv. 2018, 8, 2015-2033. [CrossRef]

18. Urquia Edreira, E.R.; Wolke, J.G.C.; Aldosari, A.A.; Al-Johany, S.S.; Anil, S.; Jansen, J.A.; van den Beucken, J.J.J.P. Effects of calcium phosphate composition in sputter coatings on in vitro and in vivo performance. J. Biomed. Mater. Res. Part A 2015, 103, 300-310. [CrossRef]

19. Eliaz, N.; Metoki, N. Calcium phosphate bioceramics: A review of their history, structure, properties, coating technologies and biomedical applications. Materials 2017, 10, 334. [CrossRef]

20. Zeng, J.; Guo, J.; Sun, Z.; Deng, F.; Ning, C.; Xie, Y. Osteoblastic and anti-osteoclastic activities of strontium-substituted silicocarnotite ceramics: In vitro and in vivo studies. Bioact. Mater. 2020, 5, 435-446. [CrossRef] 
21. BS EN ISO 14577 International Organization for Standardization. Metallic Materials: Instrumented Indentation Test for Hardness and Materials Parameters. Verification and Calibration of Testing Machines; ISO: Geneva, Switzerland, 2002.

22. Kozelskaya, A.I.; Kulkova, S.E.; Fedotkin, A.Y.; Bolbasov, E.N.; Zhukov, Y.M.; Stipniece, L.; Bakulin, A.V.; Useinov, A.S.; Shesterikov, E.V.; Locs, J.; et al. Radio frequency magnetron sputtering of Sr- and Mg-substituted $\beta$-tricalcium phosphate: Analysis of the physicochemical properties and deposition rate of coatings. Appl. Surf. Sci. 2020, 509, 144763. [CrossRef]

23. Callen, B.W.; Lowenberg, B.F.; Lugowski, S.; Sodhi, R.N.S.; Davies, J.E. Nitric acid passivation of Ti6A14V reduces thickness of surface oxide layer and increases trace element release. J. Biomed. Mater. Res. 1995, 29, 279-290. [CrossRef]

24. França, R.; Samani, T.D.; Bayade, G.; Yahia, L.; Sacher, E. Nanoscale surface characterization of biphasic calcium phosphate, with comparisons to calcium hydroxyapatite and $\beta$-tricalcium phosphate bioceramics. J. Colloid Interface Sci. 2014, 420, 182-188. [CrossRef]

25. Lu, H.B.; Campbell, C.T.; Graham, D.J.; Ratner, B.D. Surface characterization of hydroxyapatite and related calcium phosphates by XPS and TOF-SIMS. Anal. Chem. 2000, 72, 2886-2894. [CrossRef]

26. Wu, D.; Isaksson, P.; Ferguson, S.J.; Persson, C. Young's modulus of trabecular bone at the tissue level: A review. Acta Biomater. 2018, 78, 1-12. [CrossRef]

Publisher's Note: MDPI stays neutral with regard to jurisdictional claims in published maps and institutional affiliations. 